Eighteen patients had a body mass index greater than 40 , and in three of these it was over 50. Clearly, in this type of patient the medical risks of obesity are considerable. When simply dietary restriction has failed, and as an alternative to surgical approaches, very low calorie diets can provide an effective method of producing considerable weight loss. Even during prolonged use, when administered under medical supervision with appropriate monitoring, they seem to be safe.

University Department of Medicine,

Michael J Hall Bristol Royal Infirmary,

Bristol BS2 8HW

1 Felig P. Very low calorie protein diets. N Engl f Med 1984;310: 589-91.

2 Hall MJ, Goodison D, Barry RE. Low energy liquid diet in the outpatient management of refractory obesity. Clin Sci 1985; 68:74.

SIR,-I agree with many of Professor J V G A Durnin's comments about very low calorie diets (20 June, $p$ 1565) but would take issue with him on two points.

Firstly, he states that skeletal muscle protein is lost. Nitrogen balance studies, of which three have already been published and two are to be published in the near future, ${ }^{1-3}$ show that when the protein released into the body amino acid pool as fat tissue is lost is taken into account there is no negative nitrogen balance. ${ }^{4}$ There is no evidence of protein loss from muscles or organs. There is a reduction in fat free mass (lean body mass), as measured by electrical impedance, hydrodensitometry, and potassium-40, but this is all accounted for by the fluid changes caused by the diuresis that occurs with very low calorie diets (D Brodie et al and S Kreitzman et al, Association for the Study of Obesity meeting, June 1987).

Secondly, the restriction to one month's use is for one month's use at a time if dieters are not being seen by their practitioners. Under medical control many dieters have used the diet continuously for periods of a year or longer with no adverse effects and with an average weight loss of about $6 \mathrm{~kg}$ per month. Normal dietetic treatment, which Professor Durnin advocates; does not produce a satisfactory continued weight loss, which is why very low calorie diets have become so popular.

I would agree with Professor Durnin that any weight loss may be maintained only by a return to a sensible eating pattern with a reduced intake of calories. Current studies, however, suggest that the change in eating pattern that very low calorie diets provide coupled with the achievement of the target weight, often for the first time for many years, encourages many people to change their eating habits and to maintain their target weight (M A Kirchner et al, fifth international congress on obesity, Jerusalem, September 1986). The long term results are thus better than those achieved with conventional diets.

JOHN MARKS

Girton College, Cambridge University

Cambridge CB3 0JG

1 Howard AN, McLean Baird, I. A long term evaluation of very low calorie semisynthetic diets: an inpatient/outpatient study with egg albumin as the protein source. Ini 7 Obes 1977; with

2 Wilson JHP, Lamberts SWJ. Nitrogen batance in obese patients receiving a very low calorie liquid formula diet. Am $\mathcal{J} C$ lin $N u$ receiving a very $1979 ; 32: 1612-6$.

3-Ditschuneit H, Wechsler JG, Ditschuneit HH. Clinical ex perience with a very low calorie diet. In: Blackburn GL, Bray GA, eds. Management of obesity by severe caloric restriction. Littleton, Massachusetts: PSG Publishing Company, 1985.

4 James WPT, Davies HI, Bailes J, Dauncey MJ. Elevated metabolic rates in obesity. Lancet 1978; ;:1122-5.

5 Stunkard AJ, McLaren-Hume $M$. The result of treatment for obesity. Arch Intern Med 1959;103:79-86.
Nuclear magnetic resonance imaging

SIR,-Professor R E Steiner (20 June, p 1570) emphasises the value of nuclear magnetic resonance imaging in neuroradiology. We would also like to mention its place in the investigation of pituitary tumours.

By its ability to show cerebrospinal fluid and blood vessels, nuclear magnetic resonance imaging provides images of the pituitary region that combine the historical methods of pneumoencephalography and angiography as well as showing tumour tissue arising within the gland. Thus preoperative invasive methods are no longer required. The great challenge of pituitary imaging is to detect microadenomas; recent work in the United States shows that magnetic resonance imaging with a high field magnet ( 1.5 tesla) assesses the site and size of these tumours more accurately than the best computed tomography, ${ }^{1}$ and the information thus attained is a prerequisite of successful surgery. Our experience in this centre confirms the value of this method in showing such tumours.

With regard to the imaging of infants and young children, the length of the procedure and the need for the patient to be absolutely motionless make sedation an unreliable method even in expert hands. We believe that general anaesthesia is justifiable and have found that a Boyle machine, delivering gases through long tubes, may stand quite safely in the corner of a large magnet room with no risk of gas cylinders flying into the magnet or of interference with the radio frequency coils degrading the images.

C E BENNETT

R D HOARE

Magnetic Resonance Imaging Centre,

Churchill Clinic,

London SE1 7PW

Kucharczyk W; Davis DO, Kelly WM, Sze G, Norman D, Newton TH, Pituitary adenomas: high
at 1.5 T. Radiology 1986;161:761-5.

\section{Prevention of recurrent acute cystitis by methenamine hippurate}

SIR,-Contrary to what Dr S Cronberg and colleagues imply (13 June, p 1507), there is abundant evidence from controlled trials of healthy adult women "free from renal disease" that methenamine salts have a prophylactic effect. ${ }^{1-3}$ Thus Dr Cronberg and coworkers start from a false premise in claiming that the efficacy of methenamine in preventing recurrent urinary infections "has remained questionable." It is particularly unfortunate that they chose to justify their claim by quoting workers who studied a totally different group of patients-namely, paraplegic and quadriplegic patients with indwelling catheters, who are notoriously difficult to keep free from urinary infections.

We are surprised that the authors are unaware of the progress made over the past 20 years in the management of the type of patient they describe. Methenamine hippurate, while still useful, has been superceded by more effective agents for the control of recurrent urinary infections-for example, comparative clinical trials have established the superiority of trimethoprim (with, or preferably without, sulphamethoxazole) and of nitrofurantoin over methenamine salts. ${ }^{24}$

Our recent work has shown that trimethoprim is now less effective than nitrofurantoin because of the emergence of bacterial resistance. ${ }^{5}$ We have since found, however, that cephradine $(250 \mathrm{mg}$ at night $)^{6}$ or norfloxacin (200 mg at night, unpublished findings) are each about as effective as nitrofurantoin. In addition, norfloxacin (a new fluorinated 4-quinolone) has been on the market in Sweden for over one year (Lexonor)

Thus we consider the present agents of choice for long term, low dose prophylaxis to be nitrofurantoin (the macrocrystalline form, Macrodantin, being preferred because it is more acceptable to patients), norfloxacin, and cephradine. Each of these agents is more effective clinically than methenamine salts, and all have the clear advantage of being taken as small tablets or capsules only once daily. These factors are very important in improving patient compliance, which is recognised as a major problem. We are aware of special problems of pulmonary toxicity with nitrofurantoin in the Nordic races, which would have to be taken into consideration when choosing treatment.

Problems such as this and trimethoprim resistance ${ }^{5}$ highlight the need for the development of compounds suitable for the unfortunate group of patients who are plagued by recurrent attacks of urinary infections. Doctors responsible for treating infrequent infections have a wide choice of agents for short term treatment. By contrast, management of patients with frequent attacks (six or more each year) poses a much more difficult problem. Long term, low dose treatment allows around $90 \%$ of patients to enjoy a better quality of life and is cost effective. Unfortunately, there are few drugs available for this treatment. Despite this the decreasing interest in methenamine in the United Kingdom is reflected by the fact that over the past 10 years two proprietary preparations have been withdrawn from the market, leaving only one product (methenamine hippurate, marketed as Hiprex) available. This is presumably because methenamine salts are regarded by most workers in the United Kingdom as second line treatment and are not often used. We wonder why their popularity in Sweden continues in view of the availability of better alternatives.

W BRUMFITT J M T HAMILTON-MILLER

Department of Medical Microbiology,

Urinary Infection Clinic,

Royal Free Hospital and School of Medicine,

London NW3 2 QG

Brumfitt W, Pursell R, Franklin I, Davies BID. Prevention of recurrent urinary infection in females with prophylactic chemotherapy (methenamine mandelate) with or without diuresis. In: Daikes GK, ed. Proceedings of the 8th internutionul diuresis. In: Daikes GK, ed. Proceedings of the 8th internutionul congress on chemotherapy. A

2 Harding GKM, Ronald AR. A controlled study of antimicrobial prophylaxis of recurrent urinary infection in women. $N$ Engl $f$ Med 1974;291:597-601.

3 Kasanen A, Sundquist H, Elo J, Anttila M, Kangas L. Secondary prevention of urinary tract infections. Ann Clin Res 1983;15 (suppl 36): 1-36.

4 Brumfitt W, Cooper J, Hamilton-Miller JMT. Prevention of recurrent urinary infections in women: a comparative trial between nitrofurantoin and methenamine hippurate. $\mathcal{f} \mathrm{Urol}$ 1981;126:71-4.

Brumfitt w, Smith GW, Hamilton-Miller JMT, Gargan RA. A clinical comparison between Macrodantin and trimethoprim for prophylaxis in women with recurrent urinary infections. $J$ Antimicrob Chemother 1985;16:111-20.

Brumfitt W, Hamilton-Miller JMT. Recurrent urinary infections in women: clinical trial of cephradine as a prophylactic agent. Infection (in press)

AUTHORS' REPLY - We congratulate Professor Brumfitt and Dr Hamilton-Miller on knowing which would be the winning horse. As stated in our report, the open crossover study by Harding and Ronald, ${ }^{1}$ which used methenamine mandelate in combination with ascorbic acid, gave similar results to ours, which used methenamine hippurate alone. The Finnish investigation was published earlier without statistical analysis and disregarding the discrepancy between the groups in the number of cases of chronic pyelonephritis. ${ }^{2}$ Other investigations quoted in the letter are 